\title{
Current-Voltage Characterization of Silicon Quantum Dot Solar Cells
}

\author{
Dong-Ho Kim* \\ Functional Coatings Research Group, Korea Institute of Materials Science(KIMS), Changwon 641-831, Republic \\ of Korea
}

(Received April 17 2009, Accepted August 11 2009)

\begin{abstract}
The electrical and photovoltaic properties of single junction silicon quantum dot solar cells are investigated. A prototype solar cell with an effective area of $4.7 \mathrm{~mm}^{2}$ showed an open circuit voltage of $394 \mathrm{mV}$ and short circuit current density of $0.062 \mathrm{~mA} / \mathrm{cm}^{2}$. A diode model with series and shunt resistances has been applied to characterize the dark current-voltage data. The photocurrent of the quantum-dot solar cell was found to be strongly dependent on the applied voltage bias, which can be understood by consideration of the conduction mechanism of the activated carriers in the quantum dot imbedded material.
\end{abstract}

Keywords: Silicon quantum dot, Solar cell, Photocurrent, Conduction mechanism

\section{INTRODUCTION}

One of the approaches for improving energy conversion efficiency beyond the theoretical limit $(31 \%)$ of a single junction solar cell is to use a tandem device by stacking solar cells of different bandgaps. High efficiency tandem solar cells realized up to date, however, usually involve expensive materials and fabrication[1].

All-Si tandem solar cells make use of inexpensive silicon thin-film technology in combination with a high efficiency multi-bandgap approach. When silicon is made very thin (in the order of a few nanometers) in one or more dimensions, quantum confinement causes its effective bandgap to increase. Quantum dot (QD) superlattices can be used as higher bandgap cells in a tandem stack[2].

Several experimental works have been undertaken on the fabrication and characterisation of $\mathrm{Si}$ nanocrystals embedded in dielectric matrices such as oxide $[3,4]$ and nitride[5]. Previous results have shown that the size of the QDs can be tuned by adjusting the thickness of the Si-rich oxide (SRO) layers, whereas the density of the dots can be varied by changing the composition of the SRO layers[3]. The effects of doping on the structural, optical emission and electrical properties of the $\mathrm{QD} / \mathrm{SiO}_{2}$ multilayer films were also investigated[6].

However, little has been reported on the photovoltaic properties of Si quantum structures. Recently, heteroface solar cells using phosphorus-doped $\mathrm{Si} \mathrm{QD}$ on p-type crystalline $\mathrm{Si}$ substrate were fabricated and their photovoltaic properties were examined according to the QD size[7]. While promising, it is difficult to determine whether or not the photovoltaic effect comes from the quantum dots in the hetero-junction device. Rölver et al. reported the photovoltaic properties of $\mathrm{Si} / \mathrm{SiO}_{2}$ multiple quantum wells (QWs) embedded in lateral Schottky contacts[8]. In this work we have fabricated a prototype solar cell using Si QDs as an active layer on insulated substrates.

*Author to whom corresponding should be addressed: electronic mail: dhkim2@kims.re.kr

\section{EXPERIMENTS}

Details on the preparation of Si QDs in an oxide matrix and their characterization are given in Refs. 6 and 7. In brief, alternating layers of $\mathrm{SiO}_{\mathrm{x}}(\mathrm{x} \sim 0.7) / \mathrm{SiO}_{2}$ with controlled thicknesses ( $4 \mathrm{~nm}$ and $2 \mathrm{~nm}$, respectively) are deposited on Si wafers with a $1 \mu \mathrm{m}$ thick thermally-grown oxide using magnetron co-sputtering of $\mathrm{Si}$ and synthetic quartz. Doping atoms (boron or phosphorous) are incorporated into each SRO layers during the deposition to later form a p-n junction in the device. The sample is then subject to annealing at $\sim 1100^{\circ} \mathrm{C}$ to form Si QDs. SIMS measurements were performed to investigate the depth profiles of dopants before and after the annealing. As shown in Fig. 1, hightemperature annealing resulted in the smearing of dopants from each region and changing the intrinsic region into ntype because of the relatively large amount of phosphorous doping in this work.

An interdigitated device structure (Fig. 2) was fabricated by photolithography and reactive ion etching processes.

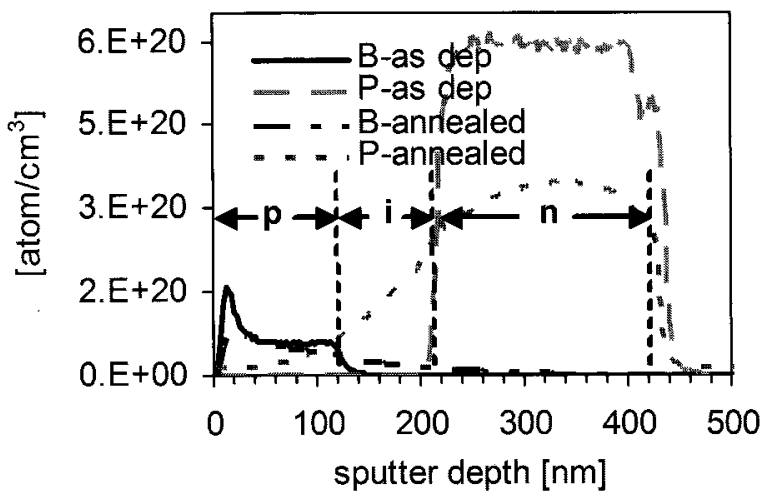

Fig. 1. Depth profiles of the dopants in a Si QD solar cell measured by SIMS. P-type layer of thickness of $120 \mathrm{~nm}$ is composed of 20 borondoped $\mathrm{SRO} / \mathrm{SiO}_{2}$ bi-layers. Intrinsic $(90 \mathrm{~nm})$ and n-type layers $(210 \mathrm{~nm})$ are composed of $15 \mathrm{SRO} / \mathrm{SiO}_{2}$ bi-layers and 35 phosphorous-doped $\mathrm{SRO} / \mathrm{SiO}_{2}$ bi-layers, respectively. 


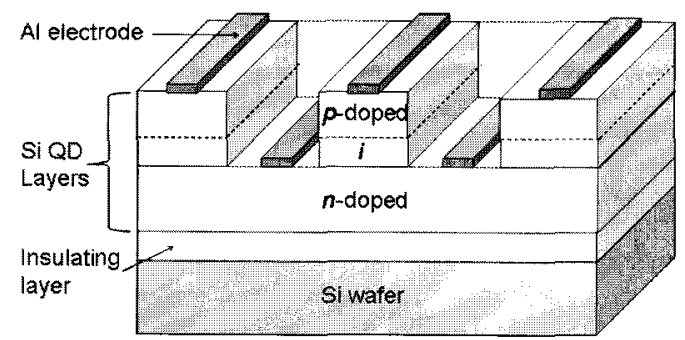

Fig. 2. Schematic of a prototype Si QD solar cell. Note that the large electrode pads for external contact are not shown and layer thicknesses are not to scale.

Aluminium contacts formed by thermal evaporation are connected to each upper (p-type) or lower (n-type) electrode pad. The size of the prototype device is $3.5 \times 2.5 \mathrm{~mm}^{2}$ and the effective area is about $4.7 \mathrm{~mm}^{2}$ due to shading by the contacts. Dark and illuminated current voltage (I-V) measurements were carried out by the use of an automatic measuring system comprised of a DC voltage-current source/monitor (Advantest, TR6143) and temperature controller. Photovoltaic properties were examined under approximatly standard test conditions (AM1.5G spectrum, $100 \mathrm{~mW} / \mathrm{cm}^{2}$ ).

\section{RESULTS AND DISCUSSION}

As shown in Fig. 3, the fabricated Si QD device exhibits diode I-V characteristics and photovoltaic behaviour. Values of the open circuit voltage $\left(\mathrm{V}_{\mathrm{oc}}\right)$ and short circuit current density $\left(\mathrm{J}_{\mathrm{sc}}\right)$ measured at $25^{\circ} \mathrm{C}$ are $394 \mathrm{mV}$ and $0.062 \mathrm{~mA} / \mathrm{cm}^{2}$, respectively. Even if the current extraction is limited to such a low level due to the nature of the QD layer, where Si QDs are embedded in dielectric matrix, this result is quite promising. For comparison, the characteristic parameters of a Schottky-type Si QW device with a QW thickness of $4 \mathrm{~nm}$ were reported to be $191 \mathrm{mV}$ and $5.1 \times 10^{-4}$ $\mathrm{mA} / \mathrm{cm}^{2}$, respectivley[8]. It was also found that the photocurrent collection is strongly dependent on the applied voltage in our prototype Si QD device, which means that the superposition approximation $\left(\mathrm{J}(\mathrm{V})=\mathrm{J}_{\mathrm{D}}(\mathrm{V})-\mathrm{J}_{\mathrm{sc}}\right)$ does not hold.

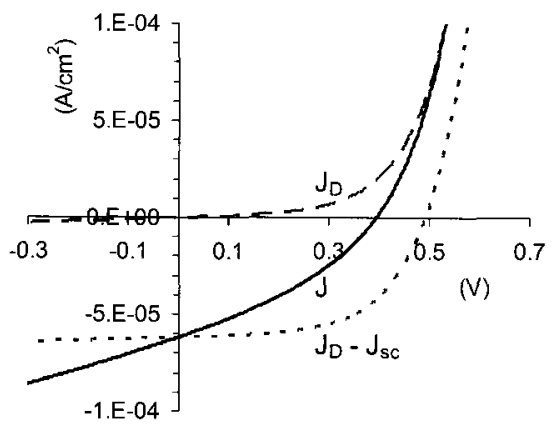

Fig. 3. Dark and illuminated I-V curves of a prototype Si QD solar cell measured at $25^{\circ} \mathrm{C}$. The ideal I-V curve based on the linear superposition assumption is also given.
In order to understand the electrical characteristics of the device, dark I-V data were analysed with a diode model. The forward bias diode current can be expressed by the formula

$$
J_{D}(V)=J_{0}\left[\exp \left(q / n k T \times V_{j}\right)-l\right]+V_{j} / R_{s h}
$$

with a dark saturation current density $\mathrm{J}_{0}$, a diode ideality factor $n$, and a shunt resistance $R_{s h}$. The junction voltage $V_{j}$ is corrected for a series resistance as $V-J \times R_{s}$. The procedure used in Ref 9 was adopted to determine values of the parameters. When the derivative $\mathrm{dV} / \mathrm{dJ}$ is plotted against $1 / \mathrm{J}$ (as shown in Fig. 4(a)), the slope is $\mathrm{nkT} / \mathrm{q}$ and the intercept is $R_{s}$. Plotting $\log \left(J_{D}\right)$ against $V_{j}$ also yields a straight line with slope $q / n k T$ and intercept $J_{0}$ (not shown here). Values of the parameters obtained from the plots for dark I-V data measured at different temperatures are given in Table 1.

With increasing temperature, the series resistance and ideality factor decrease while the dark saturation current density increases. The shunt resistance can be determined by plotting a straight line of the shunt current in the low bias range, which is the second term in the right hand side of Eq. (1) (e.g. $\mathrm{R}_{\mathrm{SH}}=1.2 \times 10^{5} \Omega \cdot \mathrm{cm}^{2}$ at $25^{\circ} \mathrm{C}$ ). Figure 4 (b) shows that there is no distinct difference between the

Table 1. Series resistance, ideality factor, and dark saturation current density extracted from dark I-V data measured at various temperatures.

\begin{tabular}{cccc}
\hline \hline $\mathrm{T}\left({ }^{\circ} \mathrm{C}\right)$ & $\begin{array}{c}\mathrm{R}_{\mathrm{s}} \\
\left(\Omega \cdot \mathrm{cm}^{2}\right)\end{array}$ & $\mathrm{n}$ & $\begin{array}{c}\mathrm{J}_{0} \times 10^{7} \\
\left(\mathrm{~A} / \mathrm{cm}^{2}\right)\end{array}$ \\
\hline 25.0 & 98.1 & 2.98 & 1.10 \\
34.6 & 88.5 & 2.93 & 2.03 \\
44.2 & 78.2 & 2.84 & 3.29 \\
53.9 & 70.3 & 2.75 & 5.25 \\
63.6 & 62.1 & 2.68 & 8.73 \\
73.2 & 58.1 & 2.57 & 13.2 \\
\hline \hline
\end{tabular}
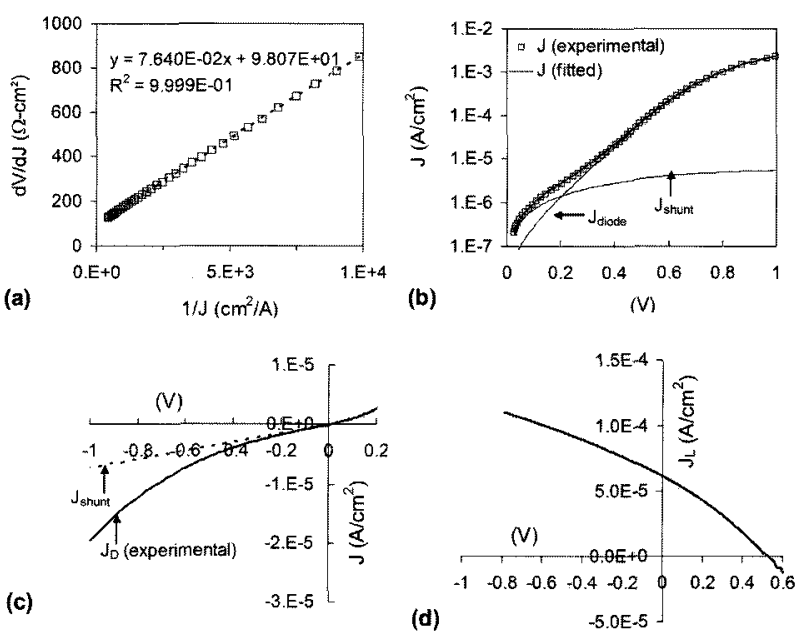

Fig. 4. Analysis of dark I-V data of a Si-QD device measured at $25^{\circ} \mathrm{C}$. (a) Plot of $\mathbf{d V / d J}$ vs $1 / \mathrm{J}$ for determination of the diode parameters and (b) experimental and fitted dark $I-V$ curves of the prototype device.; $J_{\text {diode }}$ is corresponding to the first term in the right hand side of Eq. (1) and $J_{\text {shunt }}$ to the second one. (c) The reverse bias dark current and (d) the photocurrent collection depending on the bias of the device. 
experimental and calculated values of dark current based on the diode model with fitted parameters. The close agreement observed in forward bias, however, fails in reverse bias where the leakage current increases upto $\sim 2.0 \times 10^{-5}$ at $-1.0 \mathrm{~V}$ (Fig. 4(c)). This poor rectifying behaviour of the Si QD pn-junction is due to the interdiffusion of dopants during the high temperature annealing (Fig. 1).

Figure $4(d)$ shows the photocurrent $J_{L}(V)$ obtained by subtracting the measured dark current $J_{D}(V)$ with the measured current $\mathrm{J}(\mathrm{V})$ under illumination. As mentioned above, the photocurrent depends on the applied voltage. This dependency is typically observed in amorphous silicon thin film solar cells[9]. However, the saturation of photocurrent at far reverse bias is not observed in our Si QD device. The photogenerated carriers exist in their excited state for a particular lifetime, either escaping from the QD or recombining. In order to be collected and contribute to the photocurrent, the carriers must make a series of tunneling steps, jumping from one quantum dot to the next until reaching the electrodes[10]. Since the tunneling probabilities of photogenerated carriers increase with electric field, the voltage-dependent photocurrent collection of our Si QD solar cell can be understood. Carriers can be transported by trap-assisted tunneling via defects in the $\mathrm{SiO}_{2}$ matrix. In (n-type) $\mathrm{Si} \mathrm{QD} /(\mathrm{p}$-type) c-Si heteroface devices, a high current density in the device was ascribed to a resonance tunneling between defect sites in the matrix and the quantum state in the QDs[7]. However, there are complex issues that must be understood, for example, the defect-mediated tunneling, the charging effects, the phononassisted tunneling, and the thermal activation in QD structures[11].

\section{CONCLUSIONS}

A single junction Si QD solar cell was fabricated and its photovoltaic properties were examined. It is shown that the junction properties of the device can be modelled with a diode model and the voltage-dependent photocurrent collection is due to the conduction mechanism of photogenerated carriers via tunneling. Although this preliminary device is promising towards the realization of all-silicon tandem solar cells based on Si QD materials, $V_{o c}$ should be increased above that of the standard cystalline $\mathrm{Si}$ solar cells $(>700 \mathrm{mV})$ and the current be improved in orders of magnitude for practical usage of the QD cell as a top cell in the tandem device.

\section{ACKNOWLEDGMENTS}

The author gratefully acknowledges the support by the Korea Research Foundation Grant funded by the Korean Government (MOEHRD) (KRF-2007-611- D00015). The author also thanks the members of the third generation group at the ARC Photovoltaics Centre of Excellence in University of New South Wales (Australia) for their contributions.

\section{REFERENCES}

[1] J. F. Geisz, S. Kurtz, M. W. Wanlass, J. S. Ward, A. Duda, D. J Friedman, J. M. Olson, W. E. McMahon, T. E. Moriarty, and J. T. Kiehl, Appl. Phys. Lett. 91, 023502 (2007).

[2] M. A. Green, Third Generation Photovoltaics, (Springer, Berlin, 2003), p. 104

[3] M. Zacharias, J. Heitmann, R. Scholz, U. Kahler, M. Schmidt, and J. Blasing, Appl. Phys. Lett. 80, 661 (2002).

[4] G. Conibeer, M. Green, E.-C. Cho, D. König, Y.-H. Cho, T. Fangsuwannarak, G. Scardera, E. Pink, Y. Huang, T. Puzzer, S. Huang, D. Song, C. Flynn, S. Park, X. Hao, and D. Mansfield, Thin Solid Films 516, 6748 (2008)

[5] T.-W. Kim, C.-H. Cho, B.-H. Kim, and S.-J. Park, Appl. Phys. Lett. $\mathbf{8 8}, 123102(2006)$.

[6] X. J. Hao, E. C. Cho, C. Flynn, Y. S. Shen, S. C. Park, G. Conibeer, and M. A. Green, Sol. Energy Mater. Sol. Cells 93, 273 (2009).

[7] E.-C. Cho, S. Park, X. Hao, D. Song, G. Conibeer, S.-C. Park, and M. A. Green, Nanotechnology 19, 245201 (2008).

[8] R. Rolver, B. Berghoff, D. L. Batzner, B. Spangenberg, and H. Kurz, Appl. Phys. Lett. 92, 212108 (2008).

[9] S. H. Steven, Prog. Photovolt: Res. Appl. 5, 151 (1997).

[10] O. Jani and C. Honsberg, Sol. Energy Mater. Sol. Cells 90, 3464 (2006).

[11] T. Nowozin, A. Marent, M. Geller, D. Bimberg, N. Akcay, and N. Oncan, Appl. Phys. Lett. 94, 042108 (2009). 